\title{
BANCO DE LECHE HUMANA: ESTRATEGIA PARA LA DISMINUCIÓN DE LA MORBIMORTALIDAD NEONATAL INSTITUTO NACIONAL MATERNO PERINATAL
}

\author{
Zulema Frieda León Mauricio ${ }^{1}$, Carmen Villanueva Medina² ${ }^{2}$ Carmen Dávila Aliaga ${ }^{3}$
}

\begin{abstract}
RESUMEN
El Instituto Nacional Materno Perinatal (INMP) dentro de las estrategias puestas en práctica con el objetivo de reducir la tasa de morbimortalidad contando con la asesoría técnico de Brasil, inauguró en el 2010 el primer Banco de Leche Humana del país, con la finalidad de alimentar con leche materna de su propia madre o con leche materna donada pasteurizada, total o parcialmente a los prematuros nacidos en nuestra institución, primordialmente a los nacidos con un peso $\leq$ a 1500 gramos, así como también a los recién nacidos post quirúrgico. El BLH Responsable por acciones de promoción, protección y apoyo a la lactancia materna, realiza los procesos de procura (captación de la donantes, consejería en lactancia, etc); procesamiento ó pasteurización de la leche humana (de este proceso sale la leche segura) y el fraccionamiento y distribución de acuerdo a la indicación médica. Para cumplir con nuestra labor contamos con el apoyo de nuestros centros de acopio, así como las madres que se solidarizan dentro y fuera del INMP, y donan el excedente de su leche, para apoyarnos en el cumplimiento del objetivo.

Responsable por acciones de promoción, protección y apoyo a la lactancia materna. La captación y selección de madres donantes las que reciben orientación y consejería en técnicas de amamantamiento, extracción manual, conservación, almacenamiento de leche materna y medidas de bioseguridad.
\end{abstract}

Palabras clave: Banco de Leche Humana;Morbilidad neonatal; Mortalidad neonatal (Fuente DeCS BIREME).

\section{HUMAN MILK BANK: STRATEGY FOR THE REDUCTION OF NEONATAL MORBIDITY AND MORTALITY - NATIONAL MATERNAL PERINATAL INSTITUTE}

\begin{abstract}
The National Maternal Perinatal Institute (INMP), within the strategies implemented with the objective of reducing the morbidity and mortality rate with the technical advice of Brazil, inaugurated in 2010 the first Human Milk Bank of the country, with the purpose of feeding With mother's milk from her own mother or with breast milk donated pasteurized, totally or partially to the preterm born in our institution, primarily to those born with a weight $\leq 1500$ grams, as well as to post-surgical newborns. The BLH Responsible for actions of promotion, protection and support to breastfeeding, performs the processes of procuring (donor recruitment, lactation counseling, etc); Processing or pasteurization of human milk (from this process comes safe milk) and fractionation and distribution according to medical indication. In order to carry out our work, we have the support of our collection centers, as well as the mothers who show solidarity within and outside the INMP, and donate the surplus of their milk, to support us in achieving the goal.
\end{abstract}

Key words: Human Milk bank;Neonatal morbility; Neonatal mortality (Source: MeSH NLM).

\section{INTRODUCCIÓN}

Organizaciones como la Organización Mundial de la Salud (OMS), la Academia Americana de Pediatría, el Fondo Internacional de Emergencia de las Naciones Unidas para la Infancia (UNICEF) y el Ministerio de Salud, reconocen a la leche humana como el mejor alimento para los recién nacidos. Por ende el mejor alimento para todo recién nacido es la leche materna, idealmente de su propia madre; sin embargo en circunstancias en las que esto no es posible, tenemos la opción de Los Bancos de Leche Humana (BLH), quienes han sido uno de los elementos estratégicos más importantes de la política estatal a favor de la lactancia materna. Uno de los modelos más importantes en el mundo es Brasil, quien implemento su primer BLH en octubre de 1943, actualmente cuentan con 218 bancos de leche a nivel nacional y encabezan la red global de Bancos de Leche Humana, conformada por 20 países, dentro de los que se encuentra Perú, con 3 Bancos de Leche Humana, el primer Banco de Leche funciona en el Instituto Nacional Materno Perinatal (INMP) desde Agosto del 2010, luego se incorporan el Hospital Nacional San Bartolomé, y el Hospital Regional "El Carmen" de Huancayo.

El Banco de Leche Humana es responsable por acciones de promoción, protección y apoyo a la Lactancia materna, como también de la recolección de la leche materna de las donantes, de su procesamiento (Pasteurización), control de calidad y distribución para la alimentación en especial

Licenciada Nutricionista del Instituto Nacional Materno Perinatal, jefa del Servicio de Banco de Leche Humana. Lima Perú

Licenciada Nutricionista del Instituto Nacional Materno perinatal. Lima-Perú.

Médico Pediatra Neonatóloga, docente de la Universidad Nacioanl Federico Villarreal, Directora Ejecutiva de Investigación, Docencia y Atención en Neonatología del Instituto Nacional Materno Perinatal. Lima Perú 
de los Prematuros que nacen en INMP. En el INMP nacen en promedio 22000 recién nacidos vivos (rnv), de los cuales un $9 \%$ son prematuros y un $1.5 \%$ son menores de 1500 gramos. Otros usuarios del BLH son recién nacidos con patología quirúrgica en especial digestiva, en su etapa postquirúrgica.

\section{BENEFICIOS DE LA LECHE HUMANA EN LOS NEONATOS}

La leche humana es un sistema complejo que posee más de 250 constituyentes. Entre los que se pueden mencionar: proteínas, lípidos, citocinas, electrolitos, antimicrobianos, enzimas, antiinflamatorios, inmunomoduladores y microelementos ${ }^{1}$. Lo que hace que la leche humana sea mucho más que una fuente de nutrientes, sino un fluido bioactivo de gran complejidad biológica. Sus múltiples beneficios han sido estudiados y confirmados a través del tiempo, siendo éstos de tipo biológico, nutricional, inmunológico y psicológico ${ }^{2}$. Dentro de las propiedades y componentes más importantes se encuentran:

- Enzimas: contiene Alfa 1 antitripsina la cual disminuye las enfermedades hepáticas, también contiene antigliadina que protege contra la enfermedad celiaca por lo que la lactancia materna exclusiva hasta el sexto mes de vida disminuye en un $63 \%$ el riesgo de padecerla. Alta concentración de amilasa, enzima que participa en la digestión de los alimentos ${ }^{3}$.

- Antimicrobianos: contiene bacterias (bifidobacterias) que producen en el tubo gastrointestinal ácido láctico, acético, fórmico y succínico, que reducen el $\mathrm{pH}$ intestinal inhibiendo así a las bacterias patógenas. El crecimiento de las bifidobacterias es estimulado por la presencia de factor bífido, que no es encontrado en la leche de vaca.

- Inmunoglobulinas (Ig): Inhiben las infecciones y facilitan la captura de bacterias por las células del calostro (actúan como opsoninas). El calostro de las madres de prematuros, presenta niveles más altos de Inmunoglobulina (lg), probablemente por un mecanismo de compensación. Así mismo, al ser amamantado, el bebé recibe la experiencia inmune acumulada durante toda la vida de su madre ${ }^{4}$. Entre las principales Ig tenemos:

- Inmunoglobulina A: Principal Ig de la leche humana. Posee acción antiinfecciosa específica contra: a) Enterobacterias, b) Bacterias patológicas del tracto respiratorio, c) Virus de la Polio I, II, III, d) Coxsackie, e) virus de La Influenza y otros virus.

- Inmunoglobulina M: Tiene actividad anticuerpo específica contra Enterobacterias.

- Inmunoglobulina G: Presenta actividad de anticuerpo contra virus, protozoarios y el antígeno $\mathrm{H}$ de Salmonella.

- Inmunoglobulina E: Su acción evita el contacto con antígenos maternos.
- La relación metionina-cistina adecuada para realizar la transulfuración de estos aminoácidos importante para su absorción.

- Baja capacidad tamponante, por lo que no neutraliza el PH gástrico, mejorando el metabolismo y digestión, do la probabilidad de que las bacterias patógenas lleguen al intestino y provoquen infección. En la vaca es 8 veces mayor que la leche humana lo que neutraliza el PH gástrico y disminuyen la capacidad de digestión.

- Elevada concentración de quinonas y vitamina E permiten proteger la mucosa de daños oxidativos;

- Los ácidos grasos poliinsaturados de cadena larga favorecen el desarrollo del sistema nervioso central, oligosacáridos nitrogenados posibilitan la instalación de la flora bífida, que ejercen un rol protector en el tracto intestinal;

- Los ácidos grasos de cadena larga favorecen el proceso de mielinización; la composición balanceada y la osmolaridad no permiten la ocurrencia de sobre carga para los riñones inmaduros. ${ }^{2}$

- Lactoferrina resistente a la actividad proteolítica, compite por el hierro con microorganismos patógenos como E. Coli.

- Lactoperoxidasa in vitro presenta actividad contra Estreptococos, Pseudomonas, E. Coli, S.

A largo plazo, los beneficios de la Leche Humana sugieren, efecto protector contra el riesgo de obesidad y prevención de enfermedades crónicas. ${ }^{5}$

En los últimos 20 años se demostró el impacto favorable de la lactancia materna en la evolución a largo plazo del neurodesarrollo. Lucas y colaboradores ${ }^{6}$ observaron que los prematuros alimentados con leche materna, presentan a los 8 años, mejores puntajes cognitivos, que un grupo similar alimentado con fórmula. Más recientemente la Dra. Vohr y col. ${ }^{7}$ muestra que cuanto mayor es la cantidad ingerida de leche materna mejor son los beneficios que se logran. Por cada incremento de $10 \mathrm{ml} / \mathrm{kg} / \mathrm{d}$ de leche materna, los puntajes de la prueba de Bayley, en los índices del desarrollo mental y del desarrollo psicomotor, aumentan cerca de 0,6 puntos y aún más lo hace la puntuación de la escala conductual $(0,99$ puntos) y el riesgo de rehospitalización disminuye.

Es indiscutible que la Leche Materna de la propia madre es el único alimento ideal para el recién nacido; sin embargo, en caso de lactantes imposibilitados de ser amamantados directamente por sus madres, se puede utilizar la Leche humana donada, que pasa por procesamiento de pasteurización y control de calidad obteniendo una Leche Humana Pasteurizada Segura para la alimentación del paciente, lo que se logra en el banco de leche humana (BLH).

\section{MORTALIDAD NEONATAL EN EL PERÚ}

La Dirección General de Epidemiología del Ministerio de Salud (2015), señala que la mortalidad neonatal se redujo en $69 \%$ en los últimos 20 años, sin embargo la proporción 


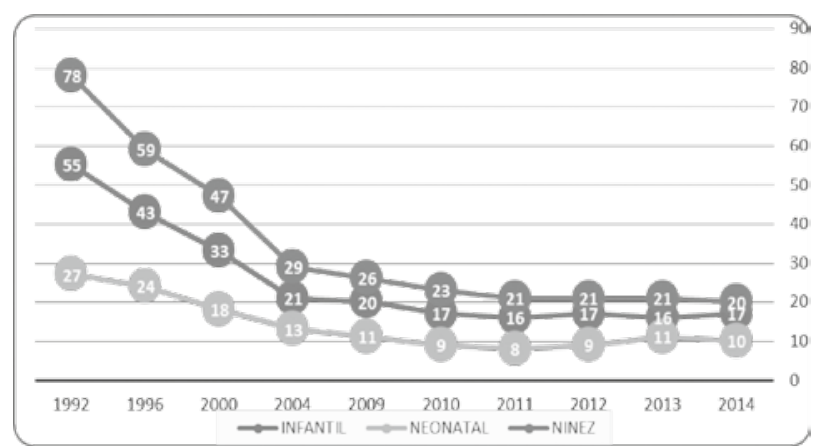

Gráfico 1. Evolución de la tasa de mortalidad neonatal, infantil y en la niñez. Perú. ENDES 1992 al 2014.

Fuente: INEI-ENDES, Dirección General de Epidemiología - MINSA

de la mortalidad neonatal frente a la mortalidad infantil se mantiene estacionaria en el tiempo; actualmente la mortalidad neonatal representa el $63 \%$ de la mortalidad infantil. Se ha reducido la brecha entre la tasa de mortalidad neonatal rural y urbana ${ }^{8}$.

Hasta el 2015 la causa de Mortalidad de los recien nacidos Prematuros en el INMP, se encontro, un $57 \%$ fue consecuencia de asfixia, un $39 \%$ malformaciones congénitas, $36 \%$ por sepsis; $16 \%$ respiratorio, Hematologico $12 \%$, HIV - HC $2 \%$; NEC $4 \%$ y Cardiopatia $2 \%$.

Frente a este panorama, una de las estrategias para la disminución de morbimortalidad neonatal es la creación de Bancos de Leche Humana, fundamental para la alimentación a favor de los prematuros.

\section{BANCO DE LECHE HUMANA EN EL INSTITUTO NACIONAL MATERNO PERINATAL}

En nuestro país aún no existe regulación nacional sobre los bancos de leche humana. El Decreto Supremo 0092006-SA, Reglamento de Alimentación Infantil, si bien regula la promoción de la lactancia materna y las acciones intersectoriales para el fomento y protección de la lactancia materna, no hace mención alguna a los Bancos de Leche Materna.

No obstante, el Instituto Nacional Materno Perinatal INMP, como una de las entidades de mayor capacidad resolutiva en la atención materno-neonatal en el país, que atiende neonatos con patologías complejas, siendo el usuario principal el prematuro extremo, requiere del mejor manejo nutricional para la recuperación de sus pacientes. En el 2010 el primer Banco de Leche Humana del Perú, inicia su funcionamiento, para atender a más de 1200 bebés prematuros, que cada año van en aumento, cuyo peso va de $500 \mathrm{~g}$ a $2500 \mathrm{~g}$, así como al incremento de los pacientes que requieren cirugía neonatal compleja (abdominal, toráxica, neurocirugía, cardiovascular).
En el 2013, el BLH se ha repotenciado a través de moderna tecnología y capacitación como resultado de la cooperación internacional brindada por el Gobierno de Brasil y la Universidad de Valencia - España.

Si bien la leche donada y procesada beneficia a todo bebé que lo reciba, los más necesitados de sus propiedades anti-infecciosas y nutricionales, especialmente son los que pesaron menos de 1500 gramos al nacer.

La creación del banco de leche humana en el INMP ha traído como consecuencia la inauguración de centros de recolección de leche materna como es el caso de la Asociación Taller de los Niños (TANI), en San Juan de Lurigancho, el convenio con el Hospital Nacional dos de Mayo y donaciones de madres que enteradas de la existencia del Banco de leche, nos contactan para ofrecerse voluntariamente como donantes, las que tienen que encontrarse en un buen estado de salud y contar con sus exámenes del control pre-natal satisfactorios (hemograma, VDRL, VIH y otras serologías), estar amamantando satisfactoriamente a su propio hijo, no fumar, no consumir alcohol y no usar medicamentos incompatibles con la lactancia materna.

\section{FUNCIONAMIENTO DEL BANCO DE LECHE HUMANA}

El BLH realiza sus funciones organizados en tres procesos:

\section{PRIMER PROCESO: Procura de Leche Humana.}

Responsable por acciones de promoción, protección y apoyo a la lactancia materna. La captación y selección de madres donantes las que reciben orientación y consejería en técnicas de amamantamiento, extracción manual, conservación, almacenamiento de leche materna y medidas de bioseguridad. Además el traslado de la leche a la sala de proceso. En la sala de extracción se realiza la extracción y fraccionamiento de la leche materna de la propia madre para la alimentación de sus hijos hospitalizados, dado que la alimentación de los neonatos con leche materna de su propia madre es nuestra prioridad nos aseguramos que acudan el mayor número de madres que tienen a sus hijos hospitalizados a extraer su leche.

\section{Grafico 2: Orientación y consejeria a madres donantes}

El segundo proceso del Banco de Leche, tiene como finalidad pasteurizar la leche donada la que debe encontrarse en óptimas condiciones, inicia con el análisis sensorial, donde se tiene en cuenta el color, olor, suciedad (pelos, pestañas, etc.), también es motivo de descarte la acidez de la leche, el rango permitido es de 1 a $8^{\circ}$ dornic, cuanto más alta la acidez, reduce el valor nutricional, desestabiliza proteínas solubles y micela de caseína, reduce el valor inmunológico y altera el Flavor. Luego de Pasteurizada, la leche Humana se cultiva 


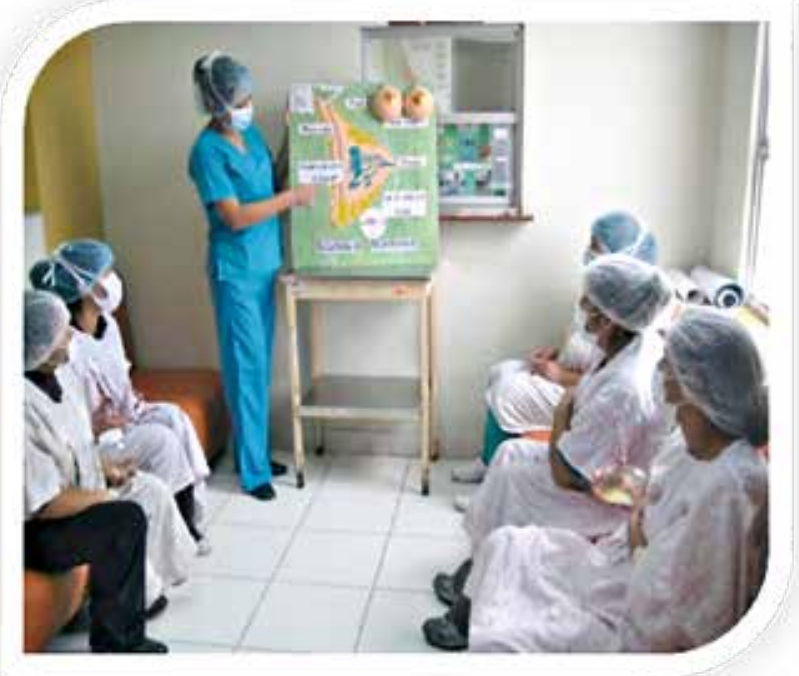

Gráfico 2. Orientación y consejeria a madres donantes

microbiológicamente por 48 horas, pasado el tiempo se procede a liberar la leche de Banco Pasteurizada que se encuentre óptima para el consumo.

\section{SEGUNDO PROCESO: Procesamiento de la Leche Humana Cruda}

Grafico 3: Análisis sensorial y físico- químico de la leche humana donada

Encargado de realizar el fraccionamiento de la leche humana pasteurizada según indicación de cada paciente y su distribución manteniendo las condiciones de esterilidad y de enfriamiento necesarios para conservar mejor el valor nutricional, se realiza a trazabilidad de la leche, de tal forma que podemos informar en cada caso, la donadora y los resultados de los controles de calidad de la leche recibida por cada niño receptor.

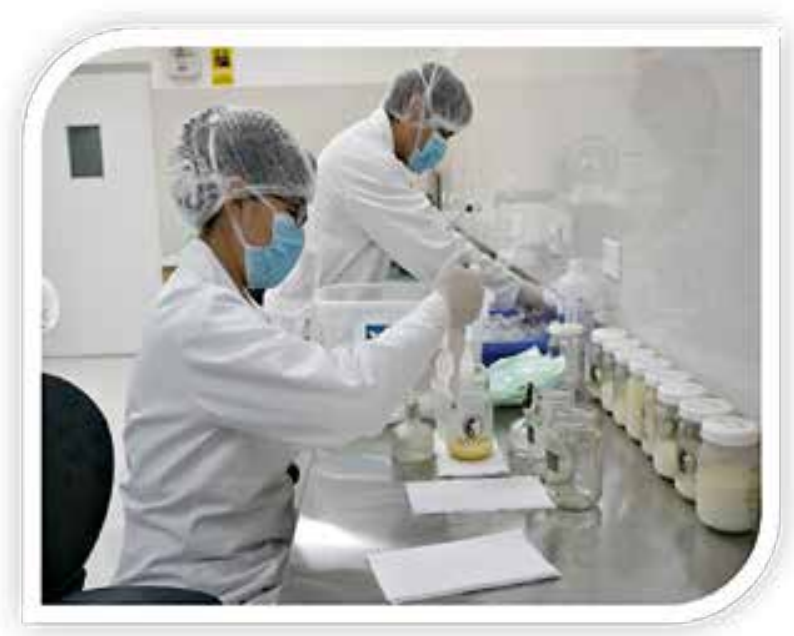

Gráfico 3. Análisis sensorial y físico- químico de la leche humana donada

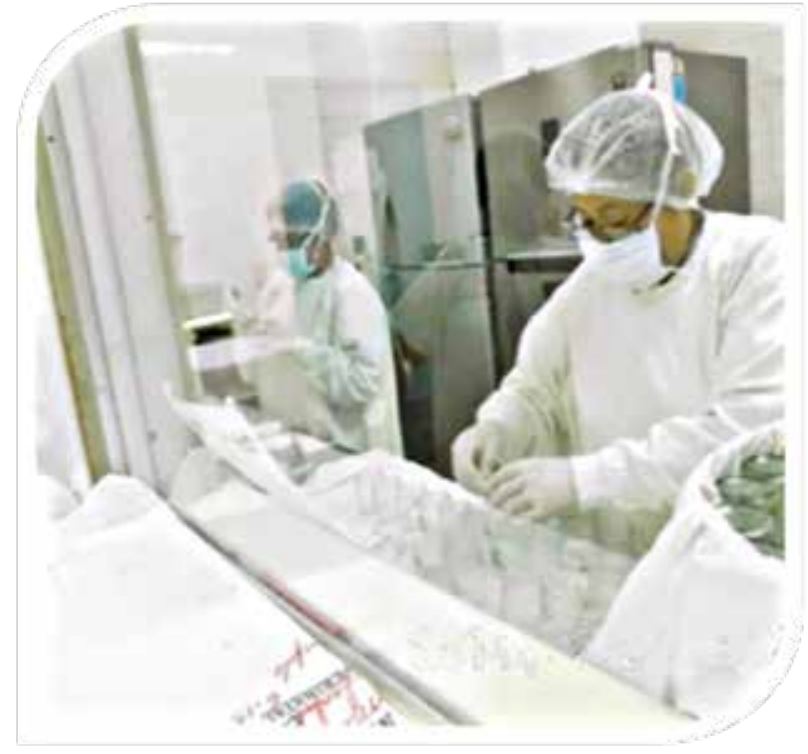

Grafico 4. Fraccionamiento de leche humana pasteurizada

\section{TERCER PROCESO: Fraccionamiento y Distribución Producción del banco de leche humana - inmp}

Desde los inicios de funcionamiento del Banco de Leche Humana del INMP, la donación de leche humana fue incrementándose gracias al aporte tanto intra o extra hospitalario. El volumen de leche humana donada extra hospitalaria en el 2016 lo constituye nuestras madres donantes de domicilio (43\%), seguido de TANI (41\%) y el Hospital Nacional Dos de Mayo (6\%). Las donación internas constituyen el $10 \%$ del total las donaciones y estan constituidas por las madres que acuden a la sala de extracción (madres que se extraen la leche para la alimentación de su propio bebé y el excedente lo donan al Banco de Leche) y las madres que atienden sus partos en la institución (después de alimentar a sus bebes el excedente lo donan al Banco de Leche). La grafica muestra el incremento del total de donaciones de leche humana.

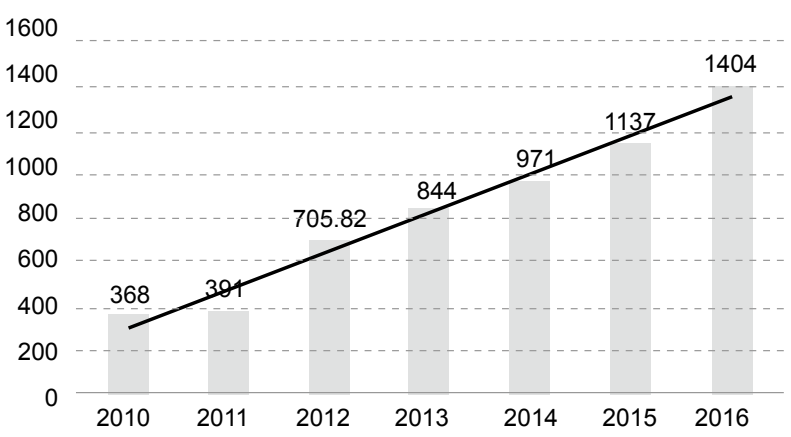

Gráfico 5. Leche humana recolectada BLH - INMP 2010 -2016

Fuente: Servicio de Banco de Leche Humana del INMP. 


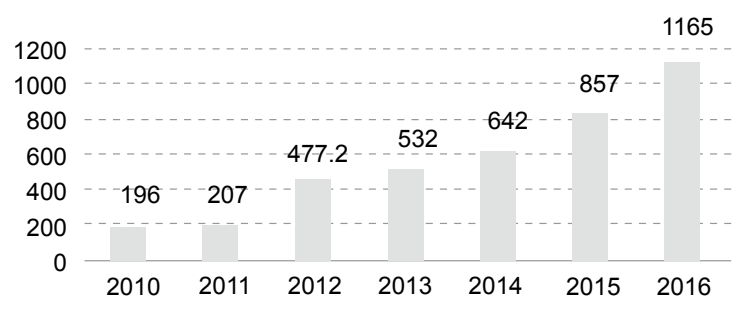

Gráfico 6: Leche humana pasteurizada BLH - INMP 2010 - 2016

Fuente: Servicio De Banco De Leche Humana Del INMP

Así mismo, ha ido en aumento el volumen de Leche humana pasteurizada lista para ser distribuida luego de pasar todos los controles de calidad, tal como se evidencia en el gráfico 6.

Durante los últimos seis años el servicio de Banco de Leche Humana del Instituto Nacional Materno Perinatal a aumentando el número de beneficiarios atendidos con leche humana pasteurizada de acuerdo a las necesidades para cada paciente. Como muestra el gráfico 7.

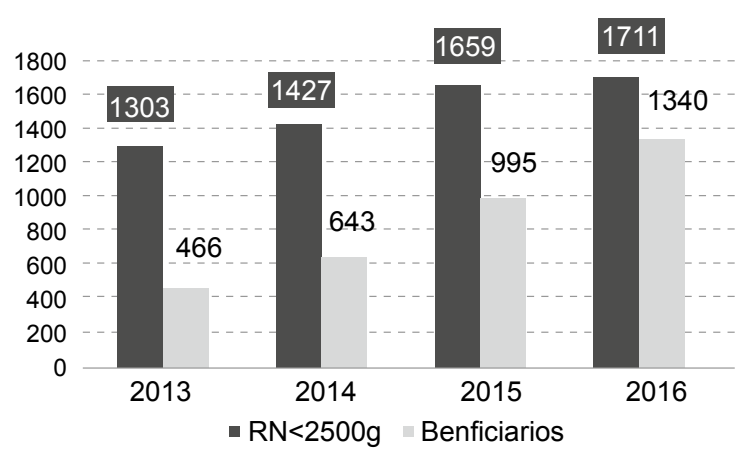

Gráfico 7. Número de beneficiarios del servicio del banco de leche del INMP

Fuente: Servicio De Banco De Leche Humana Del INMP

\section{IMPACTO DEL BANCO DE LECHE HUMANA}

A nivel nacional se ha implementado estrategias de Intervención para la reducción de la Morbimortalidad neonatal, en el marco de estas estrategias el INMP ha implementado programas de intervención, dentro de los que se considera al Banco de Leche Humana, hoy reconocido como un Servicio de Neonatología, y en el siguiente cuadro se aprecia como al transcurrir de los años fue disminuyendo la mortalidad neonatal en el INMP desde que se instaló el Banco de Leche en el 2010. Sabemos que ha habido otros factores que han disminuido este indicador, pero no dudamos que fue un factor contribuyente.
Por ser el primer banco de leche humana y referente en nuestro país tenemos como compromiso difundir la importancia de contar con un Banco de Leche Humana, los diferentes procedimientos utilizados y el manejo adecuado de la calidad de un alimento que ha sido considerado tan importante, para mejorar la morbilidad y mortalidad de nuestros pequeños pacientes, así como desarrollar en el país una política racional y eficiente de creación de bancos de leche humana.

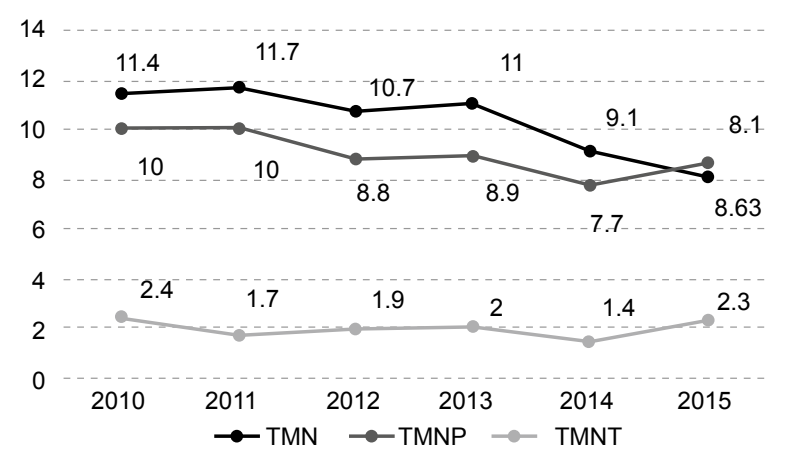

Gráfico 8. Tasa de mortalidad neonatal precoz- neonatal tardía

Fuente: Oficina Estadistica e Informática

\section{CONCLUSIONES}

1. El grupo objetivo del Banco de Leche del INMP, son los Nacidos con Muy Bajo Peso al Nacer $(<1500 \mathrm{~g})$, cuya alimentación enteral total o parcial atendemos en su totalidad, además desde que inicio el funcionamiento del BLH a la fecha extendemos la atención a los menores de $2500 \mathrm{gr}$ al nacer.

2. Conocedores de los beneficios de la Leche Humana, el Servicio de Banco de Leche del INMP tiene como objetivo fomentar la lactancia materna y promover la donación de leche humana para su posterior utilización en los neonatos principalmente prematuros y como finalidad primordial la reducción de la morbimortalidad neonatal e infantil en el Perú.

3. Los BLH no sólo cumplen un papel de proveedores de leche humana de calidad sino que actúan como centros de promoción de la lactancia materna y en este sentido, deben analizarse en el contexto de políticas y acciones que llevan a cabo los países en torno a la promoción y protección de la lactancia materna. Por ello, la coordinación de acciones con los Ministerios de Salud es también fundamental.

4. En lo que respecta al funcionamiento y acciones de los BLH en pro de la reducción de la morbi-mortalidad infantil, el personal de salud es un agente sumamente importante para la promoción de la lactancia materna y para la captación de donantes voluntarias de leche.

\section{RECOMENDACIONES}

1. Es necesario que nuestro País posea una Norma Técnica que regule la creación de la Red de Bancos de Leche, así como su funcionamiento y estos 
deben estar contemplado en el plan nacional para la reducción de la morbi-mortalidad neonatal en el País, como una estrategia de salud pública.

2. Se debe ampliar la red Nacional de bancos de Leche Humana a todas las regiones del país para mejorar el manejo nutricional de los Prematuros y pacientes con patología quirúrgica en especial digestiva.

\section{REFERENCIAS BIBLIOGRÁFICAS.}

1. Almeida, J. A. G. \& Novak, F. R. Ecologia Microbiana do Leite Humano. In: Santos Jr. (Org.). A Mama no Ciclo GravídicoPuerperal. São Paulo: Editora Atheneu, 2000.

2. Ministerio de Salud Pública y asistencia social. Programa de seguridad alimentaria y nutricional (PROSAN). Curso procesamiento y control de calidad de la leche humana. $1^{\mathrm{a}}$. Edición. Guatemala Ministerio de Salud Pública y Asistencia Social; 2011.
3. Gillman MW, et al. Risk of overweight among adolescents who were breastfed an infants. JAMA 2001; 285: 2461-7.

4. Braga LP, Palhares DB. Effect of evaporation and pasteurization in the biochemical and immunological composition of human milk. J Pediatr (Rio J). 2007;83(1):59-63

5. Von Kries R, et al. Brestfeeding and obesity: cross sectional study. BMJ 1999; 319:147-150

6. Lucas A, Morley R, Cole TJ, Lister G, Leeson-Payne C. Breast milk and subsequent intelligence quotient in children born preterm. Lancet 1992; 339:261-264.

7. Vohr BR, Poindexter BB, Dusick AM, et al. For the NICHD Neonatal Research Network. Beneficial Effects of Breast Milk in the Neonatal Intensive Care on the Developmental Outcome of Extremely Low Birth Weight Infants at 18 Months of Age. Pediatrics 2006; 118: 115-123.

8. Ministerio de Salud. Mortalidad Neonatal en el Perú y sus departamentos, 2011 - 2012. 2013. $188 p$

9. Encuesta Nacional de Salud Pública. Endes contínua. INEI ENDES 2014

ORCID iDs

Carmen Dávila Aliaga

(i) https://orcid.org/0000-0001-9411-5703 